\title{
Emotional Intelligence and Gender as Predictors of Academic Achievement among Some University Students in Barbados
}

\author{
Dr Grace A. Fayombo \\ The University of the West Indies, Cave Hill Campus \\ Faculty of Humanities and Education \\ School of Education, Barbados
}

Tel: 246-257-3998 (cell); 246-417-4435 (off) E-mail: grace.fayombo@cavehill.uwi.edu

Received: March 8, 2012

doi:10.5430/ijhe.v1n1p102
Accepted: April 19, 2012

Published: May 15, 2012

\begin{abstract}
This study investigated emotional intelligence (attending to emotion, positive expressivity and negative expressivity) and gender as predictors of academic achievement among 163 undergraduate psychology students in The University of the West Indies (UWI), Cave Hill Campus, Barbados. Results revealed significant positive and negative correlations among academic achievement, emotional intelligence components and gender. Additionally, using the stepwise multiple regression analysis, it was found that emotional intelligence contributed $40 \%(\mathrm{Rsq}=0.396)$ to the variance in academic achievement while simple regression analysis revealed that gender also contributed 5\% (Rsq $=0.048)$ to academic achievement and these results were significant indicating that both emotional intelligence and gender predicted academic achievement but emotional intelligence was a better predictor of academic achievement than gender. The Independent t-test analysis also revealed gender disparity in academic achievement and attending to emotions in favour of girls. These findings were discussed in the paper.
\end{abstract}

Keywords: UWI, Undergraduates, Academic achievement, Emotional intelligence (EI), Attending to emotions, Negative expressivity, Positive expressivity, Gender

\section{Introduction}

The term emotional intelligence was first described by Salovey and Mayer (1990) as a form of social intelligence that involves the ability to monitor one's own and others feelings and emotions, to discriminate among them, and to use this information to guide one's thinking and action. It was made popular by Goleman (1995) who refers to it as the ability to sense, understand, value and effectively apply the power and acumen of emotions as a source of human energy, information, trust, creativity and influence. Snarey and Vaillant, (1985) further suggested that the key skills and qualities needed to be successful came from within which is emotional rather than from cognitive intelligences and that emotional intelligence plays a key role in determining life success as people progress up the career ladder of their life (Kolb \& Hanley-Maxwell, 2003; Richburg \& Fletcher, 2002). These assertions explain why a person with these abilities is considered to be well adjusted and emotionally skilled; the lack of which renders an individual socially and emotionally handicapped. Nasir and Masur (2010) asserted that effective learning takes place when students have an understanding of how to learn and this understanding requires such emotional skills as confidence, self-control, the ability to communicate and cooperate with others, hence the conduct of this study to find out whether emotional intelligence influenced UWI students' academic achievement.

The theoretical model used to measure emotional intelligence in this study was Barchard (2001) Emotional Intelligence Model. She suggested that Emotional Intelligence (EI) is the ability to understand and manage one's own and other's emotions. This model was embraced by the researcher because of its comprehensive approach to measuring emotional intelligence which spans both emotional intelligence and personality traits related to emotions with seven components: positive expressivity, the tendency to express one's positive emotions nonverbally; negative expressivity, the tendency to express one's negative emotions nonverbally; attending to emotions, the tendency to attend to emotions and be aware of them; emotion-based decision-making, the tendency to make plans and decisions based on one's feelings rather than basing them on logic; responsive distress, the tendency to become distressed when in the presence of other people who are distressed, responsive joy, the tendency to become happy or cheerful when in the presence of other people who are 
happy or cheerful and lastly empathic concern, the tendency to feel concern or sympathy for those who suffer. The focus of this study is on three of the components namely: attending to emotions, positive expressivity and negative expressivity.

\section{Emotional Intelligence and Academic Achievement among the University Students.}

Literature reveals that emotional intelligence skills and competencies are essential to success and that significant positive relationships exist between emotional intelligence and academic achievement among higher education students. For instance, Nasir and Masur (2010) found that emotional intelligence significantly predicted academic achievement among the 132 students in different departments of International Islamic University, Islaabad (IIUI). Also in an earlier investigation by Rozell, Pettijohn, and Parker (2002), a significant relationship was found between emotional intelligence and CGPA of undergraduate students of Mid-Western University. Similarly among 246 Pakistan adolescents, Farooq (2003) reported that students with high emotional intelligence showed better academic performance than the students with low emotional intelligence. A similar finding among the Nigerian university students by Adeyemo (2007) revealed significant correlations between emotional intelligence and academic self-efficacy with academic achievement. Sünbül and Aslan (2008) equally reported relationship between emotional intelligence and academic achievement among 312 Education students in Konya, Turkey. Moreover, there is a significant body of research indicating that EI and other non-traditional measures are just as predictive of success as traditional IQ tests (Low, Lomax, Jackson \& Nelson 2004; Low \& Nelson 2005; Stottlemyer 2002).

There is also a growing realisation that transitions through education from school-college-career are challenging and difficult, especially for minority, first generation and non-traditional college students and that emotional intelligence influences variables in students' achievement and retention during transition period. For instance, Nelson and Low (2004; 2005); Nelson, Low \& Vela (2005) reported this among high school graduates in the first year of college in Texas universities and colleges. Likewise, Parker, Summerfeldt, Hogan and Majeski (2004) found that emotional intelligence is a predictor in identifying academically successful and academically unsuccessful students during transition period.

Additionally, research findings at the doctoral level showed significant relationships between academic performance and the skills of emotional intelligence for both high school and college students during transition in South Texas University (Stottlemyer, 2002; Vela, 2003). These studies suggested that learning and applying EI skills directly impacted the success of students during the critical transition period from high school to college and beyond and yet the influence of emotional intelligence on the academic achievement of UWI students had not been investigated. After reviewing research studies about emotional intelligence in relation to university students, Abraham (2006) concluded that training in appropriate emotional skills is necessary for career success and fulfilment.

\section{Gender and Academic Achievement}

Evidence suggests that there are gender differences and similarities in academic achievement at different levels of education around the globe. For instance, in the Caribbean, it was found at the secondary school level that there was a significant gender difference in academic achievement in favour of the girls in Barbados and St Vincent (Cumberbatch 1993; Fayombo 2010 \& Kutnick 2000). Similarly, it was also reported that among a sample of 900 students who graduated in the year 2004 from the Mona Campus of The University of the West Indies, females were more likely than males to receive honours degrees in the university (Cheeseman, Simpson \& Wint 2006).

Likewise, Dayığlu, and Türüt-Aşik (2004) found that females excel in their studies and performed better than their male counterparts among undergraduate students in a large public university in Turkey, so also Hyde and Kling (2001) reported that higher education women are often found to outperform men irrespective of the measure of success used and that women were also found to obtain better grades when compared to men than would be predicted from their SAT scores. In further investigations of gender effect on academic achievement, Betts and Morell (1999) also reported that sex remains a significant predictor of CGPA after controlling for various individual attributes such as ethnic background, SAT scores and the high school attended. Similarly, among 60,000 students from 22 public research universities, Kim, Rhoades and Woodard (2003) found that SAT scores have a significant impact on student graduation, although at the individual level, gender is a more powerful correlate of graduation than the SAT score.

Other investigators identified the strengths and weaknesses in both male and female academic abilities. For instance, it was found that female undergraduate students in Norwegian College had significantly higher self efficacy in statistics than male students but lower self efficacy in computing and marketing than male students (Busch 1995) as well as other maths-related and traditionally male-dominated subjects such as computer science (Betz \& Hackett 1983; Post-Hammer \& Smith, 1985). Likewise, Gang and Guiang (2000) reported that female students' test scores were generally higher than those of male students, but there was a very significant gender gap in scientific research among college students, with 
female students lagging well behind male students. Another growing body of research suggests that there is no gender gap in academic achievement as revealed by Habibollah, Rohani, Tengku, Jamaluddin, Kumar (2009) who found that males and females did not differ in their CGPA among 153 Iranian undergraduate students in Malaysian Universities.

\section{Present Study}

From the available literature, it is evident that there is dearth of research on the influence of emotional intelligence on academic achievement among the university students in Barbados. In spite of the previous findings on the importance of emotional intelligence on life achievement and academic success as well as the potential utility of emotional intelligence skills among higher education students, such a study had not been carried out among the UWI students in Barbados. Additionally, the literature surveyed on gender differences in academic achievement indicated mixed results with some reporting no gender disparity, some revealing females' superiority in academic achievement when compared with males and others contradicting it. It is against this backdrop that this research was conducted to find out whether emotional intelligence and gender will predict academic achievement among some undergraduate psychology students in UWI, Barbados with the aim of suggesting training in appropriate emotional skills necessary for academic achievement, career success and fulfilment. The study posits that emotional intelligence and gender are significant predictors of academic achievement.

\section{Research Questions:}

1) Will there be significant relationships between the predictor variables (attending to emotions, positive expressivity, negative expressivity, gender) and academic achievement?

2) What are the relative contributions of the predictor variables to academic achievement?

3) What are the combined contributions of the predictor variables to academic achievement?

4) Will male and female students' academic achievement and emotional intelligence be significantly different?

\section{Methods}

\subsection{Participants}

The participants were 163 undergraduate psychology students in Learning Theory and Practice Course in The University of the West Indies, Cave Hill Campus, Barbados, 2010/2011 session. Their age ranged between 16- 51years (Mean age 23.0years, SD = 7.4years). There were 65 males and 98 females, 98 from the Faculty of Humanities \& Education, 55 from Social Sciences and 10 from Pure and Applied Sciences; 149 were Barbadians while others were from other Caribbean Islands- St Vincent, Trinidad and Tobago, St Lucia, Jamaica, Dominica and Grenada and also from Canada .

\subsection{Measures}

The two instruments used for data collection were:

1) Barchard (2001) Emotional intelligence scale.

2) Academic Achievement Scale

The first instrument, Barchard (2001) Emotional intelligence scale has two sections: Section A contains the demographic variables such as; gender, age, faculty etc. Section B consists of 29 positively and negatively worded items designed to measure the different components of emotional intelligence with sample items like:

- Attending to Emotions

○ "Think about the causes of my emotions",

○ "Rarely think about how I feel"

- Positive Expressivity

○ "Express my affection physically",

- "Have difficulty showing affection".

- Negative Expressivity

- "Can't help but look upset when something bad happens",

- "Keep my feelings to myself, regardless of how unhappy I am".

All the items have the Likert format requiring the participants to rate their responses with corresponding scores: 1: Very Inaccurate; 2: Moderately Inaccurate; 3: Neither Inaccurate nor Accurate; 4: Moderately Accurate; 5: Very Accurate. 
Barchard (2001) reported the following gender-specific internal consistency values for each of the three components, ranging from 0.75 to 0.83 Cronbach's Alpha Coefficients as shown in table 1 .

$<$ Table 1 about here $>$

A pilot study was carried out among 40 UWI students to ensure the suitability of the instrument for the Caribbean environment and also to ascertain its reliability and the following Cronbach's Alpha reliability coefficients were obtained as shown in table 2:

$<$ Table 2 about here $>$

These alpha reliability coefficients of the 3 components ranging from 0.60 to 0.83 indicated that the instrument has a high internal consistency and the validity was ascertained by the choice of items which were subjected to internal consistency analysis (Cronbach's Alpha), which is an index of item homogeneity and an indication of construct validity.

The second instrument, Academic Achievement Scale assessed the students' knowledge of the topics covered in Learning Theory and Practice Course via a 50-item multiple choice test of items with four options A-D for an item. The initial versions of the instrument were given to experts for suggestions and comments before coming up with the final version. Thus, the validity of Academic Achievement Scale was ascertained by the choice of items which were subjected to internal consistency analysis and the coefficient alpha of 0.67 was obtained which is an index of item homogeneity and an indication of construct validity.

\subsection{Procedure}

Informed consent of the students to participate in the survey was obtained during the lectures prior to the administration of the questionnaires. The students were briefed of the purpose of the research and that they were free not to participate in the study. The students were surveyed in the lecture hall with the help of two research assistants who had been trained in the administration of the two instruments. The researchers took time to brief the participants on the process of answering the items in the questionnaires and that the Academic Achievement Scale is not for examination purpose, but for research and they were also told that the information would remain confidential. To buttress this, the students were told not to write their names or identification numbers on the instruments for confidentiality reasons. The researchers ensured that the two instruments were properly filled out and immediately collected, once the participants had finished responding. This was necessary because of the academic achievement test involved. The administration of the instruments lasted for approximately fifty minutes.

\subsection{Data Analysis}

The data collected were entered into the SPSS version 16.0. Descriptive Statistics, Independent t-test, Pearson Product-Moment Correlation Coefficient, Simple Regression Analysis and Stepwise Multiple Regressions were conducted. All the negatively worded items were reversed during the analysis.

\section{Results}

Research Question 1: Will there be significant relationships between the predictor variables and academic achievement?

$<$ Table 3 about here $>$

The findings displayed on table 3 revealed significant positive correlations between academic achievement and emotional intelligence components: attending to emotion $(r=.54, p<0.05)$; positive expressivity $(r=.46, p<0.05)$ and gender $(r=.22, p<0.05)$ while negative correlations existed between negative expressivity and academic achievement $(r=-.36, p<0.05)$ indicating that the more the tendency to be able to think about the causes of emotions intelligently and perhaps express affection physically the higher the academic achievement. On the contrary, the more upset the respondents appeared, the less well they achieved academically.

Research Question2: What are the relative contributions of the predictor variables to academic achievement?

\section{$<$ Table 4 about here $>$}

The second aim of this study was to estimate the relative contributions of the predictor variables to the variance in academic achievement. To this end, stepwise regression analysis and simple multiple regressions were computed with academic achievement as the dependent measure and emotional intelligence components and gender being the predictors as seen in tables 4 and 5. Emotional intelligence components were entered to find out how much variability each of them could significantly account for. As can be seen in table 4, step 1, attending to emotion alone accounted for $29 \%$ $(R$-square $=0.288)$ of the variance in academic achievement, the inclusion of positive expressivity accounted for $35 \%$ ( $R$-square 0.352$)$ which resulted in an additional $6 \%$ in step 2, negative expressivity was added in step 3 which accounted for $40 \%(R$-square $=0.396)$ resulting in an additional $4 \%$, however, in step 4 the inclusion of gender did not 
result in any additional significant relative contribution. In table 4, step 4 also, the standardized $\beta$ values revealed the decreasing order of the predictors: attending to emotion $>$ positive expressivity $>$ negative expressivity $>$ showing that attending to emotion was the best predictor, while positive expressivity and negative expressivity were other significant predictors. Thus, academic achievement was significantly predicted by attending to emotion, $(\beta=0.38, p<0.01)$, by positive expressivity, $(\beta=0.23, p<0.01)$, by negative expressivity $(\beta=0-.21, p<0.05)$. Nonetheless, in order not to miss out any information on the relative contributions of the predictor variables, a simple regression analysis was performed to find out if gender will contribute significantly to the variance in academic performance. Expectedly, findings presented on table 5 revealed that gender also contributed $5 \%(R$-square $=0.048)$ to the variance in academic achievement and this was found to be significant $(F(1,161)=8.18, p<.05)$ while emotional intelligence components contributed $40 \%$ to the variance in academic achievement which was also significant $(F(3,159)=34.74, p<.05)$. These results indicated that both emotional intelligence and gender are important variables in students' academic achievement although emotional intelligence emerged as a better predictor of academic achievement than gender in this study.

$<$ Table 5 about here $>$

Research Question 3: What is the combined effect of the predictor variables on academic achievement?

The third aim of this study was to find out the joint contributions of the predictor variables. Using the stepwise method, a significant model emerged: as seen in table 4 step 4 , these predictors significantly accounted for $41 \%$ (R-square $=$ $0.414) ;(F(5,158)=26.69, p<.05)$ of the variance in academic achievement. Therefore it was concluded that academic achievement was significantly predicted by both emotional intelligence and gender. The findings displayed on Table 6 revealed the information for the predictor tables included in the model. Gender was excluded because its relative contribution was not significant using the stepwise method, but it was significant when a separate simple multiple regression analysis was performed.

$<$ Table 6 about here $>$

Research Question 4: Will there be a significant difference between male and female students' academic achievement and emotional intelligence?

$<$ Table 7 about here $>$

The results of the Independent t-test analysis on table 6 revealed significant gender difference with the females performing better in measures of academic achievement $(\mathrm{t}=2.86, \mathrm{P}<0.05,95 \%$ CI $[-10.11,-1.85]$ and attending to emotions $(\mathrm{t}=3.66, \mathrm{P}<0.05,95 \%$ CI $[-8.31,-2.49]$ than their male counterparts. In other words, females who are better at thinking intelligently about their emotions; that also show their affections physically and manage other people's emotions may probably perform better than males academically. The non significant outcome in the measures of positive and negative expressivity however indicated that both male and female students are similar in expressing their affections physically as well as their positive and negative emotions nonverbally.

\section{Discussion}

This study investigated the relationships between emotional intelligence, gender and academic achievement. The findings revealed that academic achievement positively and significantly correlated with attending to emotions, positive expressivity as well as gender but negatively correlated with negative expressivity. These significant positive correlations between emotional intelligence and academic achievement indicated that academic success does not only depend on cognitive aspects of intelligence rather it is also affected by emotional abilities. These results were expected and a probable reason for this outcome among this UWI sample may be due to the fact that emotional intelligence is very important in life accomplishments which according to Salovey and Mayer (1990) is a form of social intelligence that involves the ability to monitor one's own and others' feelings and that the key skills and qualities needed to be successful came from within emotional rather than from cognitive intelligences (Snarey \& Vaillant 1985). Suffice to say therefore that among this sample, the participants, especially female students who attend to emotions and are aware of them are likely to think about the causes of their emotions in order to solve them intelligently which may also facilitate productive academic activities. Likewise, male and female students who are positively expressive may express their positive emotions and show affection physically which provides healthy relationship necessary for academic achievement. The negative correlation between academic achievement and negative expressivity points to the fact that male and female participants who have the tendency to express their negative expressions non verbally, who cannot help looking upset when something bad happens, may not achieve academically because of the aura surrounding them which creates negative impression.

These positive and negative correlations among emotional intelligence components and academic achievement have also generated results that are quite consistent with the existing literature in this field. The present findings for instance lend 
credence to Nasir and Masur (2010) assertion that effective learning takes place when students have an understanding of how to learn and this understanding requires emotional skills as well as their findings that emotional intelligence significantly predicts academic achievement among the students in International Islamic University Islamabad (IIUI); that a significant relationship existed between emotional intelligence and CGPA of undergraduate students of Mid-Western University (Rozell, Pettijohn \& Parker 2002) and that Pakistan adolescents students with high emotional intelligence show better academic performance than those with low emotional intelligence (Farooq 2003).

In terms of the relative contributions of the predictor variables to academic achievement using stepwise multiple regression analysis, the result exhibited on table 4 revealed that the three emotional intelligence components; attending to emotion, positive expressivity and negative expressivity relatively and significantly contributed $40 \%$ ( $R$-square $=$ $0.396)$ to the variance in academic achievement. $(F(3,159)=34.74, p<.05)$ while a separate simple multiple regression analysis revealed that gender also contributed $5 \%(\mathrm{R} \mathrm{sq}=0.048)$ to the variance in academic achievement and this was also significant $(F(1,161)=8.18, p<.05)$ indicating that emotional intelligence is a better predictor of academic achievement than gender among this sample with attending to emotion being the best predictor while positive expressivity, negative expressivity and gender were other significant predictors. That attending to emotion was the best predictor is an indication that students especially females who attend to emotions tend to think intelligently, they also control their emotions which tend to influence their cognitive abilities and they are likely to achieve best; next are male and female students who are positively expressive, who are also likely to show affection physically and therefore able to maintain healthy relationships necessary for academic achievement and lastly followed by those who are negatively expressive that is, males and females who cannot help looking upset when something bad happens, they tend to shout when they are angry or show their fear and therefore may not achieve academically because of the aura surrounding them which creates negative impression.

Another important outcome of this study is that the emotional intelligent components and gender jointly accounted for $41 \%(R$-square $=0.414)$ of the variance in academic achievement and this was found to be significant $(F(5,158)=$ 26.69, $p<.05)$ as seen on table 4 step 4 . Again, this is expected and a possible explanation for this may be due to the fact that the participants (especially females) that are emotionally intelligent and skilled tend to be potential achievers and be well adjusted the lack of which renders an individual socially and emotionally handicapped (Kolb \& Hanley-Maxwell, 2003; Richburg \& Fletcher, 2002). This finding supports a growing body of research suggesting that EI and other non-traditional measures are just as predictive of success as traditional IQ tests (Low, Lomax, Jackson \& Nelson 2004; Low \& Nelson 2005; Stottlemyer 2002) and that emotional intelligence influences variables in students' achievement and retention during the transition period of high school graduates in to the first year of college (Nelson and Low 2004). It is not surprising therefore in this study to see females that are higher in attending to emotions surpassing males in the measure of academic achievement.

In relation to gender, the result of Independent t-test analysis on table 7 showed gender disparity in only one component of emotional intelligence and academic achievement in favour of girls indicating that girls are better in the measure of emotional intelligence (attending to emotions) than their male counterparts which probably influenced their academic achievement while gender differences were not significant in other emotional intelligent components (positive expressivity and negative expressivity. The possible reason for gender disparity in emotional intelligence (attending to emotion) may be attributed to biological and genetic reasons; that certain areas of the brain dedicated to processing emotions could be larger in women than in men as reported by (Baron-Cohen, 2003 and Gur et.al 2002) and that that there is a difference in cerebral activity based on sex (Jaušovec \& Jaušovec, 2005). The finding of this study on gender disparity in academic achievement also supported the existing literature that there were significant gender differences in academic achievement in favour of the girls in Barbados and St Vincent (Cumberbatch 1993; Fayombo 2010; Kutnick 2000); among a sample of 900 students who graduated in 2004 from the Mona Campus of The University of the West Indies, (Cheeseman, Simpson \& Wint 2006) and among undergraduate students in a large public university in Turkey (Dayığlu, and Türüt-Aşik 2004). The finding of this study however contradicted that of Gang and Guiang (2000) who reported that female students lag well behind male students among college students as well as other maths-related and traditionally male-dominated subjects such as computer science (Betz \& Hackett 1983; Post-Hammer \& Smith, 1985).

\section{Conclusion}

In conclusion, the findings of this study reveal that both emotional intelligence and gender are predictors of academic achievement but emotional intelligence emerged as a better predictor of academic achievement than gender. The findings also suggest that non-cognitive aspects of intelligence should be given due consideration in educational settings to attain better educational outcomes in terms of improved academic performance especially for males. Thus a significant model using emotional intelligence components (attending to emotion, positive expressivity and negative 
expressivity) as predictors set emerged from this study suggesting training of male and female university students in appropriate emotional intelligent skills particularly attending to emotion which is the best predictor to enhance the university students' academic achievement, career success and fulfilment. It is hoped that this model will be adopted by psychologists and educators who are interested in effective teaching and learning psychology and other related disciplines in higher education as well as preventing academic failure and improving the performance of students in psychology and other related areas. Although this study had uniquely contributed to the existing literature in this area of study, more studies should be conducted to further address the relationships of other components of emotional intelligence, (empathic concern, emotion-based decision-making, responsive joy, responsive distress) and gender with academic achievement among higher education students.

\section{References}

Abraham, A. (2006). The Need for the Integration of Emotional Intelligence Skills, The Business Renaissance Quarterly, 1(3), pp. 65-79.

Adeyemo, D. A. (2007). Moderating Influence of Emotional Intelligence on the link between academic self-efficacy and achievement of university students. Psychology Developing Societies (19)2, 199-213. http://dx.doi.org/10.1177/097133360701900204

Barchard, K. A. (2001). Seven components potentially related to emotional intelligence. Retrieved June 6, 2010 [Online] Available: http://ipip.ori.org/newEmotionalIntelligenceKey.htm

Betts, J. R. and Morell, D. (1999). The Determinants of Undergraduate Grade Point Average: The Relative Importance of Family Background, High School Resources, and Peer Group Effects. The Journal of Human Resources, 34, 268-293. http://dx.doi.org/10.2307/146346

Betz, N. E., \& Hackett, G. (1983). The relationship of Mathematics self-efficacy expectations to the selections of science-based college majors. Journal of Vocational Behaviour, 23, 329-345. http://dx.doi.org/10.1016/0001-8791(83)90046-5

Busch, T. (1995). Gender differences in self efficacy and academic performance among students in Business administration. Scandanivian Journal of Educational Research, 39, 311-318. http://dx.doi.org/10.1080/0031383950390403

Cheeseman, J., Simpson, N., \& Wint, A.G. (2006). Determinants of Student Performance at the University: Reflections from the Caribbean. Research project of uwi, Mona, strategic Transformation Team. Retrieved on July 2011 [Online] Available: http://www.mona.uwi.edu/opair/research/student-performance-paper-revised.pdf

Cumberbatch, G. (1993). An investigation into the effects of gender and teacher perception on pupils' performance in mathematics in the secondary schools entrance examination in Barbados, Unpublished MA Thesis, University of the West Indies, Cave Hill, Barbados.

Dayığlu,M. \& Türüt-Aşik, S. (2004). Gender Differences in Academic Performance in a Large Public University in Turkey. Economic Research Centre, (ERC). Working Paper in Economics, Middle East Technical University Ankara, Turkey. [Online] Available: http://www.erc.metu.edu.tr/menu/series04/0417.pdf

Fariselli, L., Ghini, M. and Freedman, J. (2006). "Emotional Intelligence and Age". [Online] Available: http://www.6seconds.org/sei/ wp-age.php

Farooq, A. (2003). Effect of Emotional Intelligence on Academic Performance, Unpublished Thesis, Institute of Clinical Psychology, University of Karachi, Pakistan.

Fayombo, G.A. (2010). Gender differences in study habit, interest in schooling and attitude towards substance abuse among secondary school adolescents in Barbados. Caribbean Education Research Journal. 2(1),87-95.

Gang, C and Guiyang, X. (2000). Gender differences in academic achievement and the educational implications. Chinese Education and Society 33(2), 44-49. http://dx.doi.org/10.2753/CED1061-1932330244

Goleman, D. (1995). Emotional Intelligence. New York: Bantam Books.

Habibollah., N., Rohani., A., Tengku A. H., Jamaluddin, S. V., Mallan, K. (2009). Gender Differences in Creative Perceptions of Undergraduate Students. Journal of Applied Sciences,9(1), 167-172. http://dx.doi.org/10.3923/jas.2009.167.172

Hyde, J. S., \& Kling, K. C. (2001). Women, motivation, and achievement. Psychology of Women Quarterly, 25, 364-378. http://dx.doi.org/10.1111/1471-6402.00035 
Jausovec, N., \& Jausovec, K. (2005). Sex differences in brain activity related to general and emotional intelligence. Brain and Cognition, 59(3), 277-286. http://dx.doi.org/10.1016/j.bandc.2005.08.001

Kim, M. M., Rhoades, G., \& Woodard, D. B. (2003). Sponsored Research versus Graduating Students? Intervening Variables and Unanticipated Findings in Public Research Universities, Research in Higher Education, 44, 51-81. http://dx.doi.org/10.1023/A:1021365528640

Kolb, S.M., \& Hanley-Maxwell, C. (2003). "Critical Social Skills for Adolescents with High Incidence Disabilities: Parental Perspectives." Exceptional Children 69, 2, 163-179.

Low, G. and Nelson, D. (2004). Emotional intelligence: Effectively bridging the gap from high school to college. TAXAS STUDY Magazine for Secondary Education, 13, 2, pp. 7-10.

Low, G. and Nelson, D. (2005). Emotional intelligence: The role of transformative learning in academic excellence. Texas study of secondary Education, (XIV)2, 41-44.

Low, G.R., Lomax, A. Jackson, M. and Nelson, D.B. (2004). "Emotional intelligence: A new student development model. National Conference of the American College Personnel Association. Pennsylvania.

Nelson, D. and Low, G. (2003). Emotional intelligence: Achieving academic and career excellence. Upper Saddle River, NJ: Prentice-Hall.

Nelson, D. and Low, G. (2005). Emotional intelligence: The role of transformative learning in academic excellence. Texas Study of Secondary Education, 13, 7-10.

Nelson, D., Low, G., \& Vela, R. (2004). Emotional skills Assessment Process intervention and interpretation guide. Kingsville, TX. Texas A\&M University- Kingsville.

Nasir, M. \& Masrur, R. (2010). An Exploration of Emotional Intelligence of the Students of IIUI in Relation to Gender, Age and Academic Achievement. Bulletin of Education and Research. 32, (1), 37- 51. [Online] Available: http://pu.edu.pk/images/journal/ier/PDF-FILES/3-Revised_Article.pdf

Parker, J. D. A., Summerfeldt, L. J., Hogan, M. J., \& Majeski, S. A. (2004). Emotional intelligence and academic. success: Examining the transition from high school to university. Personality and Individual Differences, 36, 163-172. http://dx.doi.org/10.1016/S0191-8869(03)00076-X

Post-Hammer, P., \& Smith, P.L. (1985). Sex differences in career self-efficacy, consideration and interest of eighth and ninth graders. Journal of Counselling Psychology, 32, 63-81.

Richburg, M., \& Fletcher, T. (2002). Emotional intelligence: Directing a child's emotional education. Child Study Journal, 32, 31-38.

Rozell, E. J., Pettijohn, C. E. and Parker, R. S. (2002). An Empirical Evaluation of Emotional Intelligence: The impact on management development, Journal of Management Development, (21)4, 272-289. http://dx.doi.org/10.1108/02621710210430272

Salovey, P. \& Mayer, J.D. (1990). Emotional Intelligence. Imagination, Cognition, Personality, 9, 185-211.

Stottlemyer, B. G. (2002). A conceptual framework for emotional intelligence in education: Factors affecting student achievement. Unpublished doctoral dissertation, Texas A\&M University-Kingsville.

Snarey, J. R., \& Vaillant, G. E. (1985). How lower- and working-class youth become middle-class adults: The association between ego defense mechanisms and upward social mobility. Child Development, 56(4), 899-910. http://dx.doi.org/10.2307/1130102

Sünbül, A. M and Aslan, Y. (2008). The Relationship between emotional intelligence and achievement among 1st and 4th grade faculty students. Scientific Bulletin-Education Sciences Series, 2, 27-42.

Vela, R. (2003). The role of emotional intelligence in the academic achievement of first year college students. Unpublished doctoral dissertation, Texas A\&M University-Kingsville. 
Table 1. Barchard 2001 Alpha Reliablity Coefficients

\begin{tabular}{|l|l|l|l|}
\hline Components & Men & Women & No of items \\
\hline Positive Expressivity & .81 & .79 & 9 \\
\hline Negative Expressivity & .75 & .74 & 10 \\
\hline Attending to Emotions & .81 & .83 & 10 \\
\hline
\end{tabular}

Table 2. Alpha Reliability Coefficients of EI with 3 components $(\mathrm{N}=40)$

\begin{tabular}{|l|l|l|}
\hline Name of Scale & Alpha Coefficients & No of Items \\
\hline Positive Expressivity & 0.77 & 9 \\
\hline Negative Expressivity & 0.60 & 10 \\
\hline Attending to Emotions & 0.82 & 10 \\
\hline
\end{tabular}

Table 3. Correlations among Academic Achievement, Emotional Intelligence and Gender

\begin{tabular}{|l|l|l|l|l|l|}
\hline Variables & 1 & 2 & 3 & 4 & 5 \\
\hline 1) Academic Achievement & - & & & & \\
\hline 2) Attending to Emotion & $.54^{* *}$ & - & & & \\
\hline 3) Positive Expressivity & $.46^{* *}$ & $.42^{* *}$ & - & & \\
\hline 4) Negative Expressivity & $-.36^{* *}$ & $-.17^{*}$ & $-.31^{* *}$ & - & \\
\hline 5) Gender & $.22^{* *}$ & $.28^{* *}$ & .07 & -.09 & - \\
\hline
\end{tabular}

Note: ${ }^{* *}$ Significant $\mathrm{p}<0.01 ;{ }^{*} \mathrm{p}<0.05$

Table 4. Stepwise Multiple Regression Analysis predicting Students' Achievement

\begin{tabular}{|l|l|l|l|l|l|l|l|l|}
\hline & Predictors & $\mathrm{SEb}$ & $\beta$ & $\mathrm{R}-\mathrm{Sq}$ & $\Delta \mathrm{R}^{2}$ & $\mathrm{t}$ & Significance & $\mathrm{F}$ \\
\hline Step 1 & Attending to Emotions & .75 & $.54^{* *}$ & 0.288 & $.29^{* *}$ & 8.07 & .000 & 65.19 \\
\hline Step 2 & Attending to Emotions & .59. & $.42^{*}$ & & & 5.97 & .000 & \\
& Positive Expressivity & .44 & $.28^{*}$ & 0.352 & $.06^{* *}$ & 3.97 & .000 & 43.44 \\
\hline Step 3 & Attending to Emotions & .57 & $.41^{*}$ & & & 5.99 & .000 & \\
& Positive Expressivity & .34 & $.22^{*}$ & & & 3.40 & .001 & \\
& Negative Expressivity & -.26 & $-.21^{*}$ & 0.396 & $.04^{*}$ & -3.05 & .003 & 34.74 \\
\hline Step 4 & Attending to Emotions & .53 & $.38^{*}$ & & & 5.35 & .000 & \\
& Positive Expressivity & .36 & $.23^{*}$ & & & 3.30 & .002 & \\
& Negative Expressivity & -.25 & $-.21^{*}$ & & & -3.20 & .001 & \\
& Gender & .24 & .09 & 0.414 & .00 & 1.39 & .167 & 26.69 \\
\hline
\end{tabular}

Note ${ }^{* *} \operatorname{Sig} \mathrm{p}<0.01$ in steps $1,2 \& 3 ; \mathrm{p}>0.05$ in step 4

$\mathrm{SE} b$ (unstandardised coefficients showing the predicted increase in the value of the criterion variable)

$\beta$ (the standardized beta coefficients, gives a measure of the contribution of each variable to the model)

$\Delta \mathrm{R}^{2}$ (R Square Change)

$t$ (gives a rough indication of the impact of each predictor variable, the bigger the $t$ value, the larger the impact of the predictor variable on the criterion variable)

$\mathrm{R}$-sq the square of the measure of correlation and an indication that the model is fit for future prediction of academic achievement among university students. 
Table 5. Multiple Regression table showing Gender as a Predictor of Academic Achievement

\begin{tabular}{|l|l|l|l|l|}
\hline Variables & SE (B) & $\beta$ & $\mathrm{t}$ & Sig .(P) \\
\hline Gender & 2.09 & .220 & 2.86 & .05 \\
\hline Rsq $=0.048 ; *$ Sig $\mathrm{p}<0.05$ \\
$\mathrm{~F}(1,161)=8.18, \mathrm{p}<.05$ \\
\hline
\end{tabular}

Table 6. Stepwise Unstandardised and standardised regression coefficients for the variables Included in the model

\begin{tabular}{|l|l|l|l|l|l|l|l|l|}
\hline & Predictors & $\mathrm{SEb}$ & $\beta$ & $\mathrm{R}-\mathrm{Sq}$ & $\Delta \mathrm{R}^{2}$ & $\mathrm{t}$ & Significance & $\mathrm{F}$ \\
\hline Step 1 & Attending to Emotions & .75 & $.54^{* *}$ & 0.288 & $.29^{* *}$ & 8.07 & .000 & 65.19 \\
\hline Step 2 & Attending to Emotions & .59. & $.42^{*}$ & & & 5.97 & .000 & \\
& Positive Expressivity & .44 & $.28^{*}$ & 0.352 & $.06^{* *}$ & 3.97 & .000 & 43.44 \\
\hline Step 3 & Attending to Emotions & .57 & $.41^{*}$ & & & 5.99 & .000 & \\
& Positive Expressivity & .34 & $.22^{*}$ & & & 3.40 & .001 & \\
& Negative Expressivity & -.26 & $-.21^{*}$ & 0.396 & $.04 *$ & -3.05 & .003 & 34.74 \\
\hline
\end{tabular}

Note $* *$ Sig $\mathrm{p}<0.05$ in steps $1,2 \& 3$.

Note **Sig $\mathrm{p}<0.01$ in steps $1,2 \& 3$;

$\mathrm{SE} b$ (unstandardised coefficients showing the predicted increase in the value of the criterion variable)

$\beta$ (the standardized beta coefficients, gives a measure of the contribution of each variable to the model)

$\Delta \mathrm{R}^{2}$ (R Square Change)

$\mathrm{t}$ (gives a rough indication of the impact of each predictor variable, the bigger the $\mathrm{t}$ value, the larger the impact of the predictor variable on the criterion variable)

R-sq the square of the measure of correlation and an indication that the model is fit for future prediction of academic achievement among university students.

Table 7. Independent t-test comparisons of students' academic achievement and components of emotional intelligence by gender $($ Male $=65 ;$ Female $=98 ; d f=161)$

\begin{tabular}{|l|l|l|l|l|l|l|l|l|}
\hline Variables & Gender & Mean & SD & $\mathrm{t}$ & $\mathrm{P}$ & Sig & \multicolumn{2}{|c|}{$95 \% \mathrm{CL}$} \\
\cline { 3 - 9 } & & & & & & & LL & UL \\
\hline Academic Achievement & $\mathrm{M}$ & 23.26 & 14.30 & & & & & \\
& $\mathrm{~F}$ & 29.24 & 12.20 & 2.86 & .000 & $*$ & -10.11 & -1.85 \\
\hline Attending to Emotions & $\mathrm{M}$ & 30.60 & 8.12 & & & & & \\
& $\mathrm{~F}$ & 36.00 & 9.89 & 3.66 & .005 & $*$ & .8 .31 & -2.49 \\
\hline Positive Expressivity & $\mathrm{M}$ & 33.23 & 8.29 & & & & & \\
& $\mathrm{~F}$ & 33.69 & 8.71 & .34 & $\mathrm{NS}$ & .375 & -3.16 & 2.24 \\
\hline Negative Expressivity & $\mathrm{M}$ & 32.63 & 10.31 & & & & & \\
& $\mathrm{~F}$ & 30.56 & 11.84 & 1.15 & $\mathrm{NS}$ & .252 & -1.49 & 5.63 \\
\hline
\end{tabular}

Note: * significant $\mathrm{p}<.05 ; \mathrm{ns}=$ not significant $\mathrm{p}=.34 ; \mathrm{p}=1.15 ; \mathrm{M}=$ male; $\mathrm{F}=$ female; $\mathrm{CI}=$ confidence interval; $\mathrm{LL}=$ lower limit; $\mathrm{UL}=$ upper limit, $\mathrm{SD}=$ standard deviation; $\mathrm{df}=$ degrees of freedom. 